Artículo de Investigación

Apuntes del CENES

ISSN 0120-3053

Volumen $33-\mathrm{N}^{\circ} .57$

Enero - Junio de 2014

Págs. 257-286

\title{
Condiciones y determinantes de la internacionalización de las empresas industriales colombianas: una aproximación cuantitativa en el ámbito de la firma*
}

\author{
Conditions and determinants of \\ internationalization of Colombian industrial \\ companies: a quantitative approach \\ at the level of the firm
}

Héctor Alberto Botello Peñaloza** Isaac Guerrero Rincón ${ }^{* * *}$

Fecha de recepción: 5 de septiembre de 2012

Concepto de evaluación: 18 febrero de 2014

Fecha de aprobación: 21 de marzo 2014

\footnotetext{
Este artículo de investigación surge del interés de los autores por conocer los determinantes de la internacionalización de las empresas colombianas.

** Magíster en Ingeniería Industrial. Economista y profesor de la cátedra de Política Monetaria y Fiscal de la Universidad Industrial de Santander, Bucaramanga, Colombia. Correo electrónico: hectoralbertobotello@gmail.com

*** Magíster en Economía. Especialista en Gerencia Pública. Economista y profesor de Comercio Internacional de la Universidad Industrial de Santander. Director de posgrados de la Universidad Industrial de Santander, Bucaramanga, Colombia. Correo electrónico: comerciouis2010@gmail.com
} 
Condiciones y determinantes de la internacionalización de lasempresas industriales ...

Héctor Alberto Botello Peñaloza - Isaac Guerrero Rincón

\section{Resumen}

En los últimos diez años se ha visto un impulso por parte de las empresas colombianas en el ofrecimiento de sus productos en los mercados internacionales en coordinación con los demás países de América Latina. En este sentido, el objetivo de este trabajo es explorar cuantitativamente las condiciones y los determinantes que han permitido esta expansión internacional de las empresas industriales colombianas entre el 2006 y 2010. Para efectos metodológicos se utiliza un modelo logit sobre una muestra de diez mil empresas. Las estimaciones muestran que los activos específicos tales como la capacidad tecnológica y las características sectoriales de las empresas, son los factores que mayor influencia han tenido en el resultado exportador en los años de estudio.

Palabras clave: internacionalización, modelo logit, resultado exportador, características empresariales, industria, Colombia.

JEL: F10, F13, F14, P33, R15.

\section{Abstract}

In the last ten years has seen a boost by Colombian companies in offering their products in international markets in coordination with the other countries of Latin America. In this sense, the objective of this work is to explore quantitatively the conditions and determinants that have allowed this international expansion of Colombian industrial firms between 2006 and 2010. For methodological purposes is used a logit model on a sample of 10,000 companies. Estimates show that specific assets such as technological capability and characteristics by sector are the factors that have had the greatest influence on export performance in the years of study.

Keywords: internationalization, logit model, export performance, business characteristics, industry, Colombia. 


\section{INTRODUCCIÓN}

En los últimos años, la mayor parte de las economías del mundo han fomentado el libre comercio, con el objetivo de lograr un incremento en su crecimiento económico, basado en el aprovechamiento de su sector externo. Este fenómeno induce a la especialización internacionalización, elevando la productividad, gracias al uso y acceso de insumos especializados, servicios empleados, información, apoyo institucional y asistencia técnica, entre otros. Estas transformaciones crean mercados más eficientes y menores costos transaccionales, permitiendo a los agentes económicos identificar nuevos espacios para la creación de empresas y nuevas oportunidades de empleo. En este contexto, las empresas deben exponer sus cadenas de producción y de ventas a la competencia exterior ( $\mathrm{Lu} \&$ Beamish,
2001). Este proceso promueve la absorción de técnicas y conocimientos que mejoran constantemente los procesos de producción y permiten que las empresas puedan afrontar la competencia exterior, al igual que expande el mercado de compradores potenciales de los productos (Peters, 2004; García, 1994). Asimismo, el proceso de apertura estimula la innovación, ya que mejora la habilidad de las empresas para percibir oportunidades de inversión.

Colombia no ha sido ajena a este proceso $\mathrm{y}$, desde inicios de los años noventa, ha emprendido una serie de reformas que tienen el objetivo de convertirlo en uno de los países en vía de desarrollo que más ha crecido en América Latina durante los últimos años. Entre ellas, se incluyen la convertibilidad del tipo de cambio a flotación, la reducción de gravámenes a los productos externos y la firma de 
tratados de libre comercio (García, López, Uribe \& Umaña, 2014). En este orden de ideas, este trabajo investiga cuantitativamente las condiciones y determinantes de internacionalización de las empresas industriales colombianas entre el año 2006 y 2010, a fin de encontrar aquellas características que deben poseer las firmas para internacionalizarse. Para lo anterior, el artículo usa datos en el ámbito de la firma, tomados de las encuestas de empresas del Banco Mundial, para validar las características que promueven la internacionalización a través de un modelo de elección discreta.

El presente artículo se distribuye de la siguiente manera. En primer lugar, se exploran los fundamentos teóricos del proceso de internacionalización y los factores que determinan este fenómeno dentro de las empresas. En segundo lugar, se hace una revisión de la literatura empírica relacionada y se describen las principales contribuciones realizadas. A continuación se detalla la metodología y los datos que se van a utilizar. En la siguiente parte se exponen los resultados de las estimaciones realizadas, $y$, en último término, se presentan las conclusiones.

\section{LA INTERNACIONALIZACIÓN EMPRESARIAL}

Los enfoques teóricos que abordan las causas de la internacionalizan de las firmas, se alejan de las primeras aproximaciones macroeconómicas iniciadas por David Ricardo. En estas, se plantea que las ventas de los países en los mercados externos son originadas a partir de sus ventajas comparativas o absolutas, el resultado de la acumulación de recursos naturales o la casualidad histórica (Verwaal \& Donkers, 2002). Sin embargo, la literatura reciente ha cambiado hacia un enfoque microeconómico de la empresa, como unidad activa que toma decisiones en un medio competitivo, las cuales se reflejan en el conjunto de la sociedad. Estos acercamientos datan inicialmente de las ideas de Ronald Coase (1937), quien afirmaba que la decisión de la firma de internacionalizarse se basaba en la disminución de los costes, que se puede lograr mediante la externalización de ciertas operaciones, tales como la investigación, la comercialización, la contratación, etc. En este sentido, mientras mayor sea el tamaño de la organización, más altos serán los costos de su presencia en el mercado y, por ende, mayor serán los incentivos que tendrán las empresas para expandirse e integrarse a los mercados internacionales.

Un segundo enfoque, que intenta determinar las causas por las que las empresas se internacionalizan, es el definido por Dunning (1973, 1998, 1999), quien menciona que las firmas solo eligen internacionalizarse cuando pueden ampliar y explotar totalmente sus ventajas competitivas (know how, localización, calidad etc.) en aquellos mercados a los cuales puedan llegar, extendiendo su cadena de valor agregado con nuevas cuotas de mercado. Es por esta razón 
que las empresas multinacionales siempre pueden ampliar su cantidad de activos específicos (acceso exclusivo a tecnología, capital humano, etc.), que las colocan en una posición competitiva mayor que otras empresas que no lo son. Sin embargo, Renau (1996) afirma que el modelo de Dunning es solo una derivación progresiva de la teoría de Coase, ya que los fundamentos de las ventajas competitivas de la empresa proceden de los mismos procesos que se van tomando dentro de la misma, a medida que se incrementan los volúmenes de producción.

El último punto de vista es el modelo de Uppsala, y según este, se concibe la internacionalización como posiciones incrementales de la empresa en los mercados internacionales, configuradas por cuatro etapas: 1) Exportaciones ocasionales. 2) Exportación por medio de operadores independientes (franquicias o alquileres). 3) Establecimiento de unidades comerciales en el extranjero. 4) Establecimiento de sucursales productivas en el extranjero. Estas fases se logran a medida que la firma aumenta su experiencia en los mercados extranjeros, pues incrementa también su tamaño (Johanson \& Wiedersheim 1975; Johanson \& Vahlne, 1990).

FACTORES DETERMINANTES DE LA INTERNACIONALIZACIÓN DE LAS EMPRESAS

Existen múltiples investigaciones que han analizado el porqué las empresas se involucran en el mercado internacional (Bilkey, 1978; Madsen, 1987; Aaby \& Slater, 1989; Chetty \& Hamilton, 1993; Zou \& Stan, 1998; Leonidou, Katsikeas \& Samiee, 2002; Gertner, Gertner \& Guthery, 2007; Souza, Martínez López \& Coelho, 2008; Horta, 2012). No obstante, algunos autores (Zou, Taylor \& Osland, 1998; Shoham, 1998; Lages \& Lages, 2004) argumentan que no ha sido posible establecer un marco conceptual integrado que pueda encontrar los factores determinantes detrás de la internacionalización de las empresas, ya que estas se dan en un marco de interacciones complejas aleatorias. Sin embargo, existe el consenso en la literatura que explica que para estudiar el resultado de la internacionalización de las empresas, se exige el estudio de factores tanto internos como externos (Horta, 2012). La revisión que se muestra a continuación enumera estos factores y permite establecer simultáneamente las hipótesis que se comprobarán en este trabajo a través del análisis cuantitativo.

\section{Características internas}

Son los aspectos estructurales de las empresas, por ejemplo, el tamaño, la edad, la tecnología, la organización interna, etc. Estos constituyen las diferentes capacidades que le permiten a la organización competir apropiadamente en los mercados internacionales (Aaby \& Slater, 1989; Zou \& Stan, 1998; Leonidou et al., 2002; Voerman, 2004). En la literatura económica, el tamaño de la firma ha sido vinculado positivamente 
al fenómeno exportador (Verwaal \& Donkers, 2002). Para Aaby y Slater (1989) y Leonidou et al., (2002), existen tres aspectos fundamentales que justifican esta relación:

- La tenencia de mayores recursos: con mayores montos de capital (humano y físico), la empresa puede afrontar con relativa facilidad las diferentes fases de la internacionalización.

- La existencia de economías de escala: con bajos costos unitarios de producción, se pueden ofrecer productos a precios competitivos en los mercados extranjeros. Sin embargo, este punto se puede superar si la empresa compite en el extranjero por medio de la calidad y no del precio (Aaby \& Slater, 1989; Zou \& Stan, 1998).

- La posibilidad de asumir riesgos en la actividad internacional: en un primer momento, la posibilidad de internacionalizar la empresa puede requerir una inversión relevante proveniente de los recursos de capital de la empresa. Si se falla, el daño será relativamente mínimo a las finanzas corporativas en una empresa grande, en comparación con el daño a una pequeña. Estas influencias del tamaño como un aspecto positivo en la externalización de las actividades de la empresa, es un hecho respaldado empíricamente (Suárez, Olivares \& Galván, 2002; Horta, 2012). En este sentido, este trabajo se propone comprobar que:
H1: el tamaño de la empresa, entendido como mayores ventas o número de empleados, se correlaciona positivamente con la presencia internacional de la empresa.

En un criterio que va en línea con la teoría de fases incrementales Dunning, el tiempo que lleva la firma exportando/ operando tiene una influencia importante en su trayectoria. El know how asegura que la empresa pueda sobrepasar las dificultades logísticas, al mismo tiempo que ya ha podido establecer canales de distribución (Aaby \& Slater, 1989; Leonidou et al., 2002).

H2: hay una relación positiva entre los años en que la empresa viene exportando y el resultado exportador.

La presencia de capacidades tecnológicas puede contribuir a incrementar la competitividad de las empresas en los mercados exteriores (Chetty \& Hamilton, 1993). Estas afectan positivamente los procesos de organización, producción y comercialización, llevando a que las empresas puedan proveer bienes o servicios de mayor calidad y optimizar su presencia en los mercados (Alonso \& Donoso, 2000). Además, estas estrategias buscan aumentar la confianza de los clientes a través de la capacidad para elaborar bienes y servicios de calidad, causando un mejor posicionamiento en el mercado internacional y superando las barreras técnicas a la exportación. 
Por ejemplo, las empresas pueden aplicar mejores políticas de control de calidad con mayores inversiones en investigación y desarrollo, lo que conlleva la obtención de productos más uniformes, que influye positivamente en la exportación de los productos. Este aspecto ha sido investigado empíricamente y corroborado positivamente de manera significativa (Christensen, Rocha \& Gertner, 1987; Gemünden, 1991; Dhanaraj \& Beamish, 2003; Louter, Ouwerkerk \& Bakker 1991). En estos trabajos la inversión en tecnología se suele aproximar empíricamente con variables proxy tales como el licenciamiento y las certificaciones de calidad, ya que reflejan en el mercado las acciones tomadas por las organizaciones en la mejora continua de sus procesos de producción. En esta investigación se comprobará que existe una relación positiva entre las capacidades tecnológicas que puedan desarrollar las empresas y su capacidad de internacionalizarse.

H3: la inversión en tecnología (adopción de certificaciones de calidad, licencias y capacitación de los trabajadores, tenencia de TIC) se relaciona directamente con la internacionalización de las empresas.

\section{Condiciones externas}

Las empresas se desenvuelven en contextos macroeconómicos, políticos, legales y sociales que afectan sus operaciones (Porter, 1990; MeyerStamer, 2005). A pesar de esto, la mayor parte de los estudios sobre internacionalización, únicamente observan las variables internas de las firmas, aunque los estudios recientes también consideran las externas (Horta, 2012). Ejemplos son las características del mercado interno al que se enfrenta la firma (Bilkey, 1978; Zou \& Stan, 1998), las características específicas del sector (Lages \& Lages, 2004) o la intervención del gobierno (Sousa et al., 2008). En este orden de ideas, se necesita un ambiente propicio que impulse el desarrollo de la competencia, que impulse la inversión y los derechos de propiedad.

H4: si la empresa está rodeada de factores institucionales positivos, esto mejorará la probabilidad de que la empresa se involucre en un proceso de internacionalización.

Las diferencias sectoriales asociadas a las características de bienes pueden afectar el rendimiento de la demanda externa y causar variaciones en el nivel de internacionalización de las empresas. Asimismo, las variables de la localización geográfica pueden influenciar los costes a los que debe hacer frente la empresa tales como los logísticos y los del transporte de la mercancía. Encontrarse en ciudades grandes puede traer beneficios gracias a las economías de aglomeración, como consecuencia de la presencia de mayores oferentes de servicios e infraestructura, que disminuyen los costes y aumentan la probabilidad de que la empresa pueda distribuir sus productos más fácilmente. H5: es posible encontrar diferencias 
en el nivel de internacionalización y el sector económico en el que se desenvuelve la firma $y$ de su localización geográfica.

\section{Revisión de la literatura}

Debido a la amplitud del significado de internacionalización, se vio la necesidad de definir el objeto de la investigación. En general, los criterios utilizados para definir la internacionalización de la empresa son el número de filiales extranjeras (Sambharya, 1995; Gomes \& Ramaswamy, 1999), la venta extranjera ratio (Geringer, Tallman \& Olsen, 2000; Ruigrok \& Wagner, 2003), la relación de los activos extranjeros (Sambharya 1995), o el total de los ingresos de exportación (Lu \& Beamish, 2001). Sin embargo, estos criterios varían considerablemente de un sector a otro y de un país a otro.

Por ejemplo, Durán (1987) y Durán y Ubeda (1997) señalan que los montos de IED son la mejor variable proxy para medir este fenómeno. Aseguran que el objetivo del aumento de estos gastos por parte de las firmas españolas en las últimas dos décadas ha sido: incrementar o mantener su cuota en los mercados internacionales, evitar la saturación del mercado interno, aprovechar las capacidades tecnológicas que poseen y asegurar el suministro de materias primas. Sin embargo, los autores resaltan que las empresas escogen igualmente los países en los cuales establecerse en función de ciertos objetivos como impulsar inversiones comerciales en países con amplias conexiones, al igual que en países donde puedan generar más fácilmente activos estratégicos y tecnológicos. López (1997) subraya que la inversión en la Unión Europea busca cumplir con objetivos comerciales mientras que en Latinoamérica y África es para fines productivos, especialmente en la introducción en los sectores financiero y agroalimentario.

Galán, Galende y González (2000) hacen una corroboración empírica de lo anterior con base en una investigación para 34 empresas industriales y de servicios en dos provincias en España. Confirman, con base en el modelo de Dunning extendido sobre un modelo de regresión lineal, que los activos intangibles tecnológicos específicos son los factores claves para la competitividad internacional de la empresa y su grado de inversión en IED: marcas, capital humano, capacidad organizativa, actitud emprendedora de la dirección y experiencia. Este mismo comportamiento sucede cuando la variable proxy de representación de la internacionalización es el nivel de exportaciones. Sin embargo, las firmas proclives a efectuar IDE arman estructuras organizativas más complejas que las que solo exportan.

Por su parte, Wang, Hsu y Fang (2008) consideran que una empresa que tienen más de tres filiales en el extranjero puede ser catalogada como internacionalizada; empero, los autores hacen énfasis en que este es un caso único y especial de la industria taiwanesa de alta tecnología. 
A partir de este criterio se emplea un modelo logit sobre un conjunto de 114 firmas en 2005, para explorar la relación entre la condición de internacionalización y el gobierno corporativo, los gastos en investigación y desarrollo (IyD), el número de patentes, y el nivel de educación de los gerentes. Según las evaluaciones, todos los factores tienen un impacto positivo, a excepción de los montos en investigación y desarrollo, que tuvieron un efecto negativo en la internacionalización. Los autores sustentan esta relación en el hecho de que las empresas están eligiendo estrategias de crecimiento interno con una intensidad relativamente alta en IyD, frente a una estrategia de crecimiento en los mercados externos. Este hallazgo va en contracorriente con la teoría, ya que concluye que las empresas con activos específicos podrían ser disuadidas de invertir en el extranjero.

En otras aproximaciones de la internacionalización, Horta (2012) consideró utilizar el logaritmo de las exportaciones de la empresa, además, eligió igualmente por construir una variable relativa, el logaritmo de las exportaciones por persona ocupada, una especie de productividad por persona ocupada. Su análisis de los factores internos y externos de la empresa se realiza sobre las 210 empresas agroindustriales uruguayas más exportadoras en el período 2003-2006, con la ayuda de modelos factoriales y logísticos. El autor encuentra que la experiencia es la variable que más contribuye al nivel exportado, lo que confirma una de las premisas del modelo gradualista del desarrollo exportador de Duning. Sin embargo, el autor no encuentra una evidencia estadísticamente significativa entre el tamaño de la empresa y el resultado exportador, y argumenta que esta posición no tiene unanimidad en la literatura, ya que en una economía mundial globalizada con costes de transporte mínimos, el tamaño de la organización ya no tiende a ser una variable relevante.

Sin embargo, la aproximación empírica más abundante es el entendimiento de la internacionalización como la capacidad de internacionalización con el resultado exportador de la firma. En un análisis de las pymes peruanas, Mendoza (2008) explica como la propensión exportadora se ve afectada por las características internas de las empresas, mediante el uso de modelos probabilísticos. El autor encuentra que un mayor tamaño de la empresa, un nivel de educación universitaria alcanzado por la persona que dirige la empresa y una alta experiencia empresarial, son los principales factores que permiten que las empresas se internacionalicen. En esta misma línea, pero para una muestra de empresas manufactureras españolas, López (1997) halla que el nivel educativo de los trabajadores obtenido mediante las capacitaciones internas de la empresa, incrementa la capacidad de penetración exportadora en el mercado externo de la empresa, ya que permite la elaboración de productos de mayor calidad. 
Usando la misma aproximación, Ayouz, Mourad, Remaud y Hervé (2003) buscan establecer un vínculo entre la decisión de exportar y los factores internos y externos que afectan a la empresa utilizando una muestra de 335 pequeñas empresas agroalimentarias francesas. Su modelo estadístico desafía muchos planteamientos de la teoría, tal como el hecho de que sus estimaciones muestran una conexión negativa entre la alta calidad percibida del producto y el hecho de que una empresa exporte, asimismo no hay importancia del capital humano de los gerentes. Sin embargo, cuestiones internas como la integración organizacional del gerente, la característica perecedera de los productos elaborados, y externas como la presencia de normas fitosanitarias, sí tienen un impacto relevante en la estrategia exportadora. Entre otros factores internos, Barber y Cobos (2002) revelan que la actitud proactiva de los directivos de la empresa mediante una estrategia diferenciada de marketing explica la rápida internacionalización de las empresas. Belso (2003) incluye la presencia de redes empresariales en el modelo determinante del resultado exportador, y sostiene que estas tienen un papel activo significativo en el crecimiento exportador de las pymes, ya que les permite exportar de manera indirecta y sobreponerse a los altos costes de las exportaciones.

En resumen, se pueden extraer dos tendencias generales en la revisión de la literatura. La primera muestra que la mayoría de los estudios empíricos actuales se han concentrado principalmente en los aspectos internos y externos de las empresas. En segundo lugar, los estudios relacionan la internacionalización de las empresas con el desempeño exportador, idea que puede argumentarse dado el bajo nivel de IED de la región (Horta 2012). Por tanto, en el presente trabajo se utilizará este tipo de aproximación para confirmar las hipótesis respectivas.

\section{LA INTERNACIONALIZACIÓN DE LAS FIRMAS COLOMBIANAS}

El proceso de internacionalización de las empresas colombianas en la última década ha estado caracterizado por un vigoroso crecimiento de la economía mundial (Tabla 1), el más alto desde hace veinte años con un promedio anual del $5,4 \%$. En la región se ha alcanzado una tasa de crecimiento anual promedio entre 2005 y 2010 del $6 \%$, incrementándose de manera significativa desde el 4,9\% alcanzado entre 2001 y 2005. Según Reyes (2013), esta tendencia ha estado sustentada en mayores precios de las materias primas que han impulsado el ingreso de mayor inversión extranjera directa (IED) y de flujos de divisas provenientes de mayores exportaciones.

En efecto, en la última década los flujos de inversión provenientes del extranjero han marcado una media del 3\% del producto interior bruto (PIB) del país (Figura 1). No obstante, el proceso no ha sido recíproco por parte de los inversionistas locales, los datos sobre inversiones regionales en el extranjero 
(INE) solo han alcanzado un promedio del $0,5 \%$ del PIB entre el año 2002 y 2012. La falta de este último elemento hace de Colombia una receptora neta de flujos de capital, al contrario del continente asiático o el medio oeste donde ambos flujos de capital son equiparables en montos y tendencias de crecimiento (Reyes, 2013)

Tabla 1. Crecimiento del producto interior bruto (PIB) por quinquenios. Precios en dólares constantes de 2005, normalizados por paridad de poder adquisitivo.

\begin{tabular}{|lcccccc|}
\hline Economías & $1980-85$ & $1986-90$ & $1991-95$ & $1996-2000$ & $2001-05$ & $2006-10$ \\
\hline Mundo & $8.2 \%$ & $7.0 \%$ & $6.7 \%$ & $5.5 \%$ & $6.1 \%$ & $5.4 \%$ \\
Avanzadas & $8.2 \%$ & $7.0 \%$ & $5.0 \%$ & $5.1 \%$ & $4.6 \%$ & $3.0 \%$ \\
Asia & $8.2 \%$ & $6.8 \%$ & $10.1 \%$ & $6.1 \%$ & $8.5 \%$ & $8.6 \%$ \\
Latinoamérica & $6.1 \%$ & $5.1 \%$ & $5.9 \%$ & $4.7 \%$ & $4.9 \%$ & $6.0 \%$ \\
África & $7.4 \%$ & $5.6 \%$ & $3.4 \%$ & $5.4 \%$ & $8.0 \%$ & $7.4 \%$ \\
Colombia & $2.3 \%$ & $4.6 \%$ & $4.6 \%$ & $0.9 \%$ & $3.4 \%$ & $4.3 \%$ \\
\hline
\end{tabular}

Fuente: Fondo Monetario Internacional. Compendio Outlook 1980- 2010.

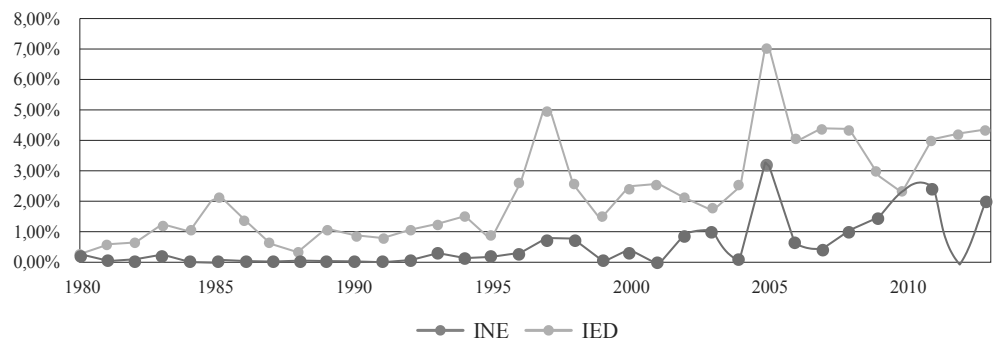

Figura 1. Evolución de la inversión extranjera directa (IED) y la inversión regional en el extranjero (INE) hacia y desde Colombia como porcentaje del PIB.

Fuente: elaboración propia con datos del Anuario 2013 de la Comisión Económica para América Latina y el Caribe

En la distribución regional, los países con mayores recursos naturales son los mismos que mayor cantidad de IED e INE acumularon en el periodo: Brasil, Argentina, México y Colombia, por los recursos petroleros; Chile y Perú con el cobre. Brasil acumuló cerca del $33 \%$ de la IED de la región, seguido por México con el $23 \%$ y Chile con el $13 \%$, resultados alcanzados por sus buenas condiciones de mercado interno y disponibilidad de recursos naturales. Este grupo de países también generaron las mayores cantidades de INE con el $22 \%$, $29 \%$ y $28 \%$, respectivamente. Sin embargo, si lo que se quiere observar es la influencia de esta inversion sobre la economía de cada pais, es necesario calcular su participacion como porcentaje del PIB. En este sentido, la economía 
chilena se muestra como la más influenciada por este proceso con un 7,6 $\%$ de IED y $4,4 \%$ de INE en el periodo de estudio. Esto, junto con su estabiliad institucional, le ha permitido aprovechar los altos precios del cobre para poder posicionarse como la economía líder en términos comerciales y logísticos entre todos los paises de América Latina

Otro indicador capaz de dar una idea del grado de apertura comercial externa por parte de la región es la aportación de las exportaciones e importaciones como porcentaje al PIB (Figura 2). Entre 1996 y el 2012, este indicador pasó de representar el $24 \%$ del PIB regional a cerca del $40 \%$, aunque se debilitó temporalmente en 2008 por causa de la crisis internacional y la consecuente baja en la demanda de Estados Unidos y Europa. Por países, el aumento de la apertura comercial ha sido una tendencia generalizada, incluso en países con indicadores de apertura bajos como Colombia, que ha doblado en la última década la participación de sus flujos comerciales desde el $19 \%$ en 1985 hasta el $35 \%$ del PIB. Este proceso en parte se sostuvo por los mayores cargamentos exportados de materias primas tales como el petróleo y el carbón. En el ámbito regional, ejemplos remarcables incluyen a Chile que ha pasado de tener una representación de un $50 \%$ del PIB entre 1990 y 2000 , a un $70 \%$ entre el 2001 y 2012.

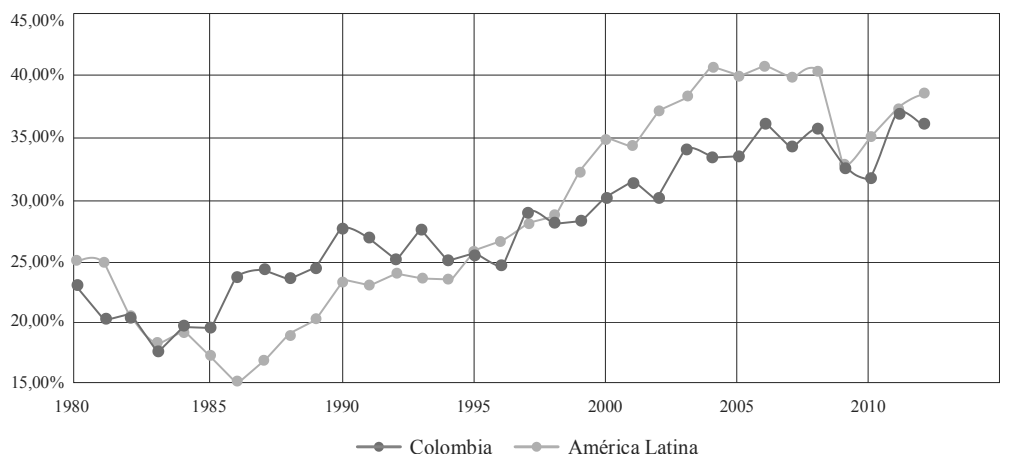

Figura 2. Relación exportaciones e importaciones sobre PIB.

Evolución en Colombia y América Latina 1980-2012.

Fuente: elaboración propia con datos del Anuario 2013 de la Comisión Económica para América Latina y el Caribe.

Como se mencionó, la ampliación de la apertura comercial en Colombia se ha debido principalmente a la dinámica de los bienes primarios que las empresas colombianas han colocado en los mercados extranjeros, situación que se puede apreciar en detalle con la Tabla 2. En esta se enseña el porcentaje de participación de los 
productos exportados entre primarios e industriales por quinquenios. La mayoría de productos han mostrado significativas variaciones en sus participaciones para cada periodo. Los cambios más importantes han sido el incremento de la participación del petróleo y del carbón, pasando del $0,1 \mathrm{y}$
$0,88 \%$ en 1980 hasta el $33 \%$ y el $13 \%$ en 2012. Otros ejemplos son el caso del oro $(4,7 \%)$ y los derivados del petróleo $(7,28$ $\%)$ contra el del café, que ha visto caer su representación sensiblemente desde el 49 $\%$ de las exportaciones en 1980 , hasta solo el 4,5\% en el 2012.

Tabla 2. Porcentaje de las exportaciones por tipo de producto exportado.

Promedios por quinquenio.

\begin{tabular}{|l|c|c|c|c|c|c|}
\hline Productos & $\mathbf{1 9 8 0 - 8 5}$ & $\mathbf{1 9 8 6 - 9 0}$ & $\mathbf{1 9 9 1 - 9 5}$ & $\mathbf{1 9 9 6 - 2 0 0 0}$ & $\mathbf{2 0 0 1 - 0 5}$ & $\mathbf{2 0 0 6 - 1 2}$ \\
\hline Petróleo & 0.1 & 15.62 & 15.54 & 24.44 & 19.70 & 33.42 \\
Carbón & 0.88 & 6.10 & 7.28 & 7.54 & 10.04 & 13.56 \\
Derivados del petróleo & 9.52 & 6.26 & 3.64 & 3.46 & 6.50 & 7.28 \\
Oro & 0.00 & 0.00 & 0.34 & 0.38 & 2.18 & 4.66 \\
Café & 49.50 & 34.30 & 18.86 & 14.34 & 6.38 & 4.52 \\
Flores & 3.72 & 3.38 & 4.78 & 4.74 & 4.88 & 2.70 \\
Productos de & & & & & & \\
polimerización & 0.00 & 0.54 & 1.52 & 2.04 & 2.90 & 2.24 \\
Productos de hierro & 0.96 & 2.30 & 1.40 & 0.92 & 2.94 & 1.96 \\
Plátanos & 4.78 & 4.46 & 5.48 & 4.32 & 3.04 & 1.78 \\
Otros & 30.64 & 27.04 & 41.16 & 37.82 & 41.44 & 27.88 \\
\hline
\end{tabular}

Fuente: elaboración propia con datos del Anuario 2013 de la Comisión Económica para América Latina y el Caribe.

En relación con el comportamiento de las empresas exportadoras (Tabla 3), los últimos diez años se han enmarcado en una disminución de las empresas que se dedicaron a esta actividad. En 2002, el número de empresas era de 10.667 , llegando a un máximo en 2005 de 12,211 para luego finalizar el 2012 con menos de 8,104 . Esta tendencia, sin embargo, ha venido de la mano de un aumento de las exportaciones promedio por empresa medido en dólares FOB, pasando de 1,1 millones en 2002 a los 7,4 millones. No obstante, estos montos están concentrados en su mayor parte en las diez empresas más grandes, con cerca del $53 \%$ de las exportaciones realizadas en 2012 cuando en 2002 era de solo el $29 \%$. Esta concentración está respaldada por el cálculo del índice de Herfindah $1^{1}$ que ha pasado desde 243 en 2002 hasta los 1000 puntos en 2012, límite considerado una concentración de mercado de acumulación moderada.

El índice de Herfindahl e Hirschman $(\mathrm{IHH})$ es una medida de uso general en economía, que trata de medir el gradode concentración en un mercado. Entre más alto el índice, más concentrado, menos competitivo el mercado. Se calcula elevando al cuadrado la cuota de mercado que cada empresa posee y sumando esas cantidades. Los resultados van desde cerca de 0 (competencia perfecta) a 10.000 (control monopólico). En el 
Condiciones y determinantes de la internacionalización de las empresas industriales ...

Héctor Alberto Botello Peñaloza - Isaac Guerrero Rincón

Tabla 3. Comportamiento de las empresas exportadoras. En dólares FOB.

\begin{tabular}{|c|c|c|c|c|}
\hline Año & $\mathbf{N}^{\mathbf{0}}$ Empresas & Prom. empresa & $\begin{array}{c}\text { Concentración } \\
\text { 10 primeros }\end{array}$ & $\begin{array}{c}\text { Índices } \\
\text { HH. }\end{array}$ \\
\hline 2002 & 10,667 & $1,122,622$ & $39.57 \%$ & 243 \\
2001 & 11,383 & $1,083,155$ & $41.22 \%$ & 253 \\
2003 & 11,756 & $1,116,755$ & $40.73 \%$ & 250 \\
2004 & 12,132 & $1,383,858$ & $39.97 \%$ & 246 \\
2005 & 12,211 & $1,735,390$ & $36.48 \%$ & 224 \\
2006 & 11,565 & $2,108,990$ & $37.24 \%$ & 229 \\
2007 & 11,442 & $2,621,162$ & $35.23 \%$ & 216 \\
2009 & 11,305 & $2,905,469$ & $42.33 \%$ & 335 \\
2008 & 10,730 & $3,506,606$ & $39.07 \%$ & 414 \\
2010 & 9,437 & $4,208,259$ & $50.14 \%$ & 675 \\
2011 & 9,555 & $5,956,561$ & $54.42 \%$ & 979 \\
2012 & 9,744 & $6,036,727$ & $58.91 \%$ & 1,104 \\
2013 & 8,104 & $7,418,899$ & $53.61 \%$ & 1,005 \\
\hline
\end{tabular}

Fuente: elaboración propia con datos del Departamento de Impuestos y Aduanas Nacionales (DIAN).

Esta breve revisión del comportamiento de los flujos de inversión y comerciales, desde y hacia Colombia, muestra una participación e inclusión más activa, pero concentrada de manera desproporcionada dentro de las empresas productoras de recursos naturales. Con este contexto, en el presente trabajo se quiere buscar los determinantes que han impulsado esta tendencia en las empresas industriales, las cuales aportan una mayor cantidad de empleo y de desarrollo económico (Boisier, 2014). A continuación se expone la metodología implementada en la investigación, se describe la fuente de datos utilizada, el modelo de cálculo escogido y los resultados alcanzados.

\section{METODOLOGÍA}

\section{Fuente de datos}

Los datos proceden de la encuesta de empresas realizada por el Banco Mundial (BM), mediante la cual se entrevista a empresas formales de los sectores de la industria manufacturera y servicios, clasificadas con los códigos 15-37, 45, 5052, 55, 60-64, y 72 (CIIU Rev.3.1). Las empresas de los sectores industriales incluyen la fabricación de confecciones, alimentos, metales y maquinaria, electrónicos, químicos y farmacéuticos, muebles, productos no metálicos, plásticos, autos y otras industrias

sistema legal de EE. UU. se considera que índices de entre 1000 y 1500 puntos reflejan una concentración de mercado moderada. Sobre 2500 puntos se considera que el mercado es demasiado concentrado. Fusiones y adquisiciones que aumenten el índice por sobre 100 puntos causan una investigación antimonopolio por parte de las autoridades. Para una explicación en profundidad de su cálculo y aplicaciones ver Berger (2013). 
manufactureras. En el sector servicios están la construcción, transporte, comunicaciones, hoteles, restaurantes, salud, educación, reparaciones $\mathrm{y}$ servicios empresariales.

Generalmente se realizan de 1200 a 1800 entrevistas personales en las economías más grandes, 360 entrevistas en las economías medianas y para las economías pequeñas, 150 entrevistas. La encuesta es contestada por los empresarios y altos directivos de las firmas y en algunas ocasiones el encuestador toma información adicional proveniente de los contadores y los directores de recursos humanos de las empresas.

La encuesta abarca diversos temas como son: las características de las empresas, la distribución de los empleados, el acceso a la financiación, ventas anuales, los costos de los insumos y la mano de obra, la composición de la fuerza laboral, la corrupción, la concesión de licencias, la infraestructura, el comercio, la innovación, la tecnología, la delincuencia, la competencia, la utilización de la capacidad, la tierra y los permisos, la fiscalidad, la informalidad y las relaciones con el gobierno.

La metodología de muestreo de las observaciones entrevistadas por la encuestada es estratificada. En este tipo de encuestas las unidades de la población se reúnen en grupos homogéneos y posteriormente se procede a elegir muestras aleatorias simples dentro de cada grupo. Este método permite mayores niveles de precisión en las medidas estadísticas al reducir los errores estándar relativamente comparados con los logrados mediante el muestreo aleatorio simple. Además, los resultados obtenidos se pueden extrapolar gracias al uso de los factores de expansión, los cuales corresponden a las ponderaciones de los conglomerados que se configuraron cuando se realizó la encuesta.

En la encuesta de empresas, los conglomerados son escogidos a partir de tres criterios: el tamaño de la empresa, el sector de actividad y la región geográfica dentro del país donde se localiza la empresa. Para definir el primer criterio se conforman tres grupos: de 1 a 19 empleados (firmas pequeñas) y de 20 a 200 (medianas) y más de 200 empleados son consideradas las grandes empresas. En relación con el tamaño de las empresas, como en América Latina la mayor parte de las empresas son pequeñas y medianas, la encuesta suele sobre-estratificar a las grandes empresas, las cuales tienden a ser los motores de la creación de empleo y de valor agregado. Por sectores, el comercio y otros servicios poseen una participación mayor sobre el empleo, la producción y el número total de establecimientos. Entre tanto, de las regiones geográficas se escogen las que contienen la mayor parte de la actividad económica. El número de establecimientos tomado para el marco muestral de la encuesta se deriva del universo de empresas elegibles obtenidas de la oficina de estadísticas de cada país. En ocasiones, la lista de las empresas se 
obtiene de otras agencias gubernamentales, como las autoridades fiscales o de las asociaciones empresariales y las bases de datos de marketing.

Para esta investigación se utilizaron las encuestas del año 2006 y 2010 realizadas por el Banco Mundial en Colombia. En esta se recopiló información de 17.000 empresas. En la Tabla 4 se muestra la distribución de las empresas analizadas por ciudad y sector que se categorizan por su tamaño.

Tabla 4. Distribución de la encuesta de empresas del Banco Mundial por país.

\begin{tabular}{|c|l|c|c|c|c|}
\hline \multicolumn{2}{|c|}{ Variable } & Pequeñas & Medianas & Grande & Total \\
\hline \multirow{5}{*}{ Ciudad } & Barranquilla & $41.6 \%$ & $49.8 \%$ & $8.6 \%$ & 642 \\
\cline { 2 - 5 } & Bogotá & $46.1 \%$ & $39.5 \%$ & $14.4 \%$ & 12,900 \\
\cline { 2 - 5 } & Cali & $63.2 \%$ & $28.3 \%$ & $8.6 \%$ & 1,075 \\
\cline { 2 - 5 } & Medellín & $52.0 \%$ & $35.1 \%$ & $13.0 \%$ & 2,386 \\
\hline \multirow{5}{*}{ Sector } & Textiles & $53.6 \%$ & $43.9 \%$ & $2.5 \%$ & 4,321 \\
\cline { 2 - 6 } & Confecciones & $34.4 \%$ & $56.8 \%$ & $8.7 \%$ & 2,940 \\
\cline { 2 - 6 } & Alimentos & $47.3 \%$ & $39.8 \%$ & $12.9 \%$ & 1,553 \\
\cline { 2 - 6 } & Metales y maquinaria & $63.5 \%$ & $28.5 \%$ & $8.0 \%$ & 1,440 \\
\cline { 2 - 6 } & Químicos y farmacéuticos & $35.9 \%$ & $21.2 \%$ & $43.0 \%$ & 3,071 \\
\cline { 2 - 6 } & Plásticos & $25.0 \%$ & $58.0 \%$ & $17.1 \%$ & 440 \\
\cline { 2 - 6 } & Otros sectores industriales & $60.0 \%$ & $32.6 \%$ & $7.4 \%$ & 3,238 \\
\hline
\end{tabular}

Fuente: cálculos del autor con base en la encuesta de empresas del Banco Mundial 2006 y 2010. A partir de esta encuesta se procedió a determinar el método por el cual se comprobarán las hipótesis planteadas en la revisión teórica.

\section{La aproximación empírica de la internacionalización}

En este trabajo se representa la tendencia a exportar como proxy de la internacionalización de la empresa. Trabajos como los de Horta (2012), Mendoza (2008) y Peters (2004) sugieren esta aproximación, dado el bajo nivel de inversión directa de las empresas latinoamericanas en el extranjero. En este sentido, una breve aproximación descriptiva de la encuesta de empresas del Banco Mundial refleja una propensión media regional a exportar alrededor del $25 \%$ (Tabla 5), resaltan las empresas de Bogotá y Cali donde el $35 \%$ de las empresas industriales encuestadas, reportó haber exportado algún producto entre 2006 y 2010. Mientras que por tamaño, las firmas pequeñas, de menos de 20 empleados, marcaron niveles del $13 \%$ contra cerca del $87 \%$ de las grandes empresas, debido a que estas últimas cuentan con estructuras industriales más representativas dentro de la base total del valor agregado de la economías (Pinon, Mejía, Garza \& 
Delgado, 2012). Lo anterior apoya la hipótesis de que la cantidad de recursos que posee la empresa influye en su capacidad de internacionalizarse.

Tabla 5. Propensión a exportar por ciudad, tamaño y sector económico.

\begin{tabular}{|c|l|c|c|c|c|}
\hline \multicolumn{1}{|c|}{ Variable } & Pequeñas & Medianas & Grande & Total \\
\hline \multirow{5}{*}{ Ciudad } & Barranquilla & $4 \%$ & $17 \%$ & $82 \%$ & $17 \%$ \\
\cline { 2 - 5 } & Bogotá & $14 \%$ & $45 \%$ & $88 \%$ & $37 \%$ \\
\cline { 2 - 5 } & Cali & $21 \%$ & $57 \%$ & $60 \%$ & $35 \%$ \\
\cline { 2 - 5 } & Medellín & $5 \%$ & $45 \%$ & $91 \%$ & $30 \%$ \\
\hline \multirow{5}{*}{ Sector } & Textiles & $7 \%$ & $58 \%$ & $96 \%$ & $31 \%$ \\
\cline { 2 - 6 } & Confecciones & $5 \%$ & $17 \%$ & $54 \%$ & $16 \%$ \\
\cline { 2 - 5 } & Alimentos & $5 \%$ & $22 \%$ & $44 \%$ & $17 \%$ \\
\cline { 2 - 6 } & Metales y maquinaria & $23 \%$ & $56 \%$ & $90 \%$ & $38 \%$ \\
\cline { 2 - 6 } & Químicos y farmacéuticos & $21 \%$ & $78 \%$ & $99 \%$ & $67 \%$ \\
\cline { 2 - 6 } & Plásticos & $30 \%$ & $35 \%$ & $85 \%$ & $42 \%$ \\
\cline { 2 - 6 } & Otros sectores industriales & $18 \%$ & $49 \%$ & $92 \%$ & $34 \%$ \\
\hline \multicolumn{7}{|c|}{} & $13 \%$ & $44 \%$ & $87 \%$ & $25 \%$ \\
\hline
\end{tabular}

Fuente: cálculos del autor con base en la encuesta de empresas del Banco Mundial 2006 y 2010.

Por sectores económicos, la propensión exportadora es alta en las industrias de los químicos y los farmacéuticos, con cerca del $67 \%$. Este fenómeno se da sin importar el tamaño de las firmas. De hecho, el $21 \%$ de las empresas de menos de 20 empleados exportan en este sector, contra un $99 \%$ de las empresas grandes. Los sectores con menor capacidad de venta al extranjero son los sectores de las confecciones y los textiles, con menos del $4,7 \%$ y $15,8 \%$ de empresas exportadoras en 2010. Este fenómeno se debe a su relativa baja competitividad externa comparada con las economías del este asiático como China y Vietnam (Calvo, 2012; Graña, Liseras, Rearte \& Barberis, 2010).

En Colombia no todas las empresas tienen la posibilidad de enviar sus exportaciones directamente a sus demandantes, dado los trámites burocráticos, trabas administrativas, normas fitosanitarias e ingentes costes de transporte. En ocasiones se realizan ventas al extranjero mediante terceros (exportaciones indirectas), con el objetivo de disminuir costes a través del outsourcing. En este sentido, según la Figura 2, cerca del 37,4\% de las firmas exporta de manera indirecta mientras un $62 \%$ lo hace directamente. Por tamaño, se aprecia que cerca del $70 \%$ de las empresas pequeñas que exportan, lo hace de manera indirecta. En el caso de las empresas grandes este porcentaje disminuye hasta el $24 \%$, ya que estas últimas tienen todos los recursos a su alcance para la creación y el montaje de los canales de distribución y la comercialización de sus productos en el extranjero. 
Condiciones y determinantes de la internacionalización de lasempresas industriales ...

Héctor Alberto Botello Peñaloza - Isaac Guerrero Rincón

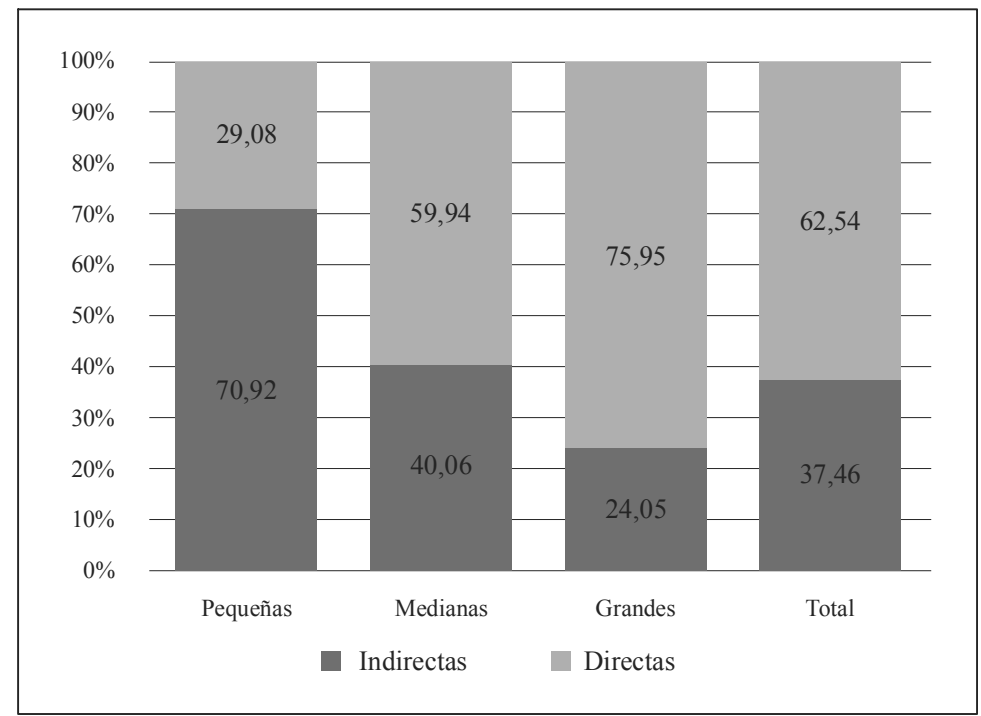

Figura 3. Tipo de exportaciones por tamaño de la empresa.

Fuente: cálculos del autor con base en la encuesta de empresas del Banco Mundial 2006 y 2010.

Este panorama resalta la importancia del tamaño de las firmas industriales como causa de su resultado exportador, sin embargo hay otro conjunto de variables, internas y externas a la organización, que explican este fenómeno. Es por esto que en la siguiente sección se presenta el modelo de estimación que permitirá el análisis de estos determinantes y la posterior comprobación de las hipótesis establecidas anteriormente.

\section{MODELO DE ANÁLISIS}

La internacionalización de la firma se aproxima empíricamente como la capacidad de la empresa para exportar. Estadísticamente, esta variable se categoriza como uno en el caso de que la empresa haya colocado sus productos en mercados extranjeros, y cero, en el caso contrario. Cuando las variables de análisis tienen estas características, de poseer únicamente dos valores, se denominan variables dicotómicas y en su estudio se implementan los modelos de elección discreta.

En general, se considera que detrás de la variable dependiente en estos modelos, $Y$, se encuentra una variable no observable, $I$, que toma ciertos valores si ha sobrepasado cierto lumbral, como se expresa a continuación y es dependiente de un conjunto de variables explicativas $X_{i}$ 


$$
\begin{aligned}
& \text { APUNTES DEL CENES N }{ }^{\circ} .57
\end{aligned}
$$

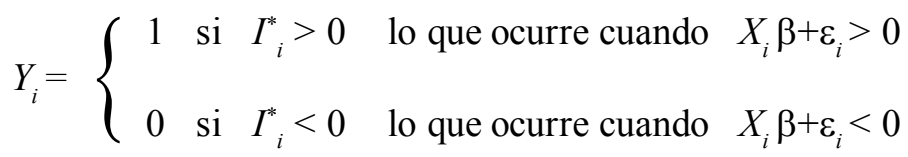

Donde el supuesto sobre la distribución de $\varepsilon$, determina el tipo de modelo por estimar: si se supone una función de distribución uniforme, se utiliza el modelo lineal de probabilidad truncado; si se distribuye como una normal con media cero y varianza uno, el modelo generado será un probit; mientras que si se supone que es mediante una curva logística, se trataría de un modelo logit. La hipótesis de que el umbral por superar por la variable latente sea cero, se puede modificar por cualquier otro valor, sugiriéndose que el valor crítico sea el definido por el término constante (Pérez, 2005).

De acuerdo con Medina (2003), bajo el primer enfoque se sugiere que el modelo probabilístico quedaría definido como:

$$
P_{i}=\operatorname{Pr} o b\left(Y_{i}=1\right)=\operatorname{Pr} o b\left(I_{i}^{*}>0\right)=\operatorname{Pr} o b\left(X_{i} \beta+\varepsilon_{i}>0\right)=F\left(X_{i} \beta\right)
$$

La efectividad de estos modelos se mide a través de dos indicadores, el primero es el grado de la varianza de la variable dependiente, captada o predicha por parte de las variables independientes, indicador denominado $\mathrm{R}^{2}$. Entre más alto, más efectivo es el modelo en determinar el comportamiento de la variable dependiente y viceversa. El segundo es el grado de observaciones del modelo que han sido clasificadas correctamente en la característica analizada, un mayor porcentaje indica que el grado de robustez del modelo es mejor.

$$
Y=f(S, X) \quad Y=\alpha+\beta_{i} X_{i}+\varepsilon
$$

Donde $Y$ es la variable para explicar o dependiente categorizada de forma dicotómica, donde 1 es si la empresa
En términos estadísticos, hay diferentes situaciones sobre la naturaleza de los datos que se deben corregir para una óptima calibración del modelo, tales como la presencia de heterocedasticidad, multicolinealidad y autocorrelación serial (Pérez, 2005).

\section{Función de estimación}

Tomando en cuenta los criterios anteriores, se propone para este trabajo la utilización de la siguiente función probabilística:

exportó, y cero en caso contrario. Por su parte, $\beta$, capta el aporte marginal de cada uno de estos factores a la probabilidad 
de exportar, mientras que $\varepsilon$ es el error de la estimación que se distribuye según la función con la que se distribuya la variable dependiente.

Esta última es explicada por un vector que resume factores característicos de la firma, $X$, que se seleccionaron con base en las hipótesis planteadas:

H1: tamaño de la empresa: se comprobó mediante el número de empleados, volumen de ventas de la empresa.

H2: edad: años de operación de la empresa.

H3: capacidad tecnológica: tenencia de email, pagina web, certificaciones de calidad, capacitación de los trabajadores en cursos de calidad.

H4: factores institucionales: la opinión del empresario sobre el sistema judicial del país donde se encuentra operando la empresa. Tenencia de cuenta bancaria y acceso al crédito.

H5: indicadores sectoriales: sector de actividad, país y tamaño de la ciudad

Asimismo se incluyeron otras variables de control para mejorar el proceso de cálculo del modelo que se estimaron en el modelo gracias al uso de variables dicotómicas.

\section{Resultados y análisis}

Después de evaluar la base de datos y validar las respuestas de la encuesta, se seleccionaron 10.960 firmas para el análisis, posteriormente se hicieron las pruebas de chi cuadrado para probar el tipo de función con el cual se distribuía la variable dependiente, y se encontró que era mediante una representación de una curva logística. Sin embargo, también se decidió calcular el modelo suponiendo una distribución de tipo probit. En este orden de ideas, la Tabla 6 muestra los resultados de las estimaciones de modelo logit con los coeficientes y elasticidades (efecto marginal) obtenidas para cada una de las variables de control (independientes) sobre la probabilidad de la empresa a exportar entre el 2006 y el 2010.

En términos del ajuste global, el modelo resulta aceptable considerando que el valor del estadístico chi $^{2}$ es muy significativo. A su vez, todas las variables introducidas presentaron niveles de significancia estadística del $5 \%$, y según el R2 ajustado, el modelo consigue explicar un $60,38 \%$ de la varianza de la variable dependiente que mide el resultado exportador, mientras que el porcentaje de casos correctamente clasificados dentro del modelo propuesto alcanzó cerca del $91 \%$. Con esta verificación de robustez del modelo, se pasa a comprobar cada una de las hipótesis propuestas por el trabajo, contrastándolas con el efecto que tengan las variables independientes con la probabilidad de exportar de la firma.

Para la interpretación de los resultados, el efecto marginal (elasticidad) en las variables continuas equivale al porcentaje 
en el que se incrementa la probabilidad de exportar, dado un cambio del $1 \%$ en la variable independiente de análisis. Para las categóricas, el efecto marginal mide la probabilidad de manera relativa como comparación de una característica base, por ejemplo, la probabilidad de que una empresa mediana exporte, es un $42 \%$ mayor que en una empresa pequeña. Con estos parámetros también se pueden estimar las probabilidades absolutas de exportar, si se posee o no una característica; esta última perspectiva es la utilizada en la mayor parte de las corroboraciones de las hipótesis planteadas.

Sobre la primera y segunda hipótesis, los cálculos confirman que el tamaño y la edad de la empresa se correlacionan positivamente con el resultado exportador. En términos absolutos, las empresas con menos de 20 empleados (medianas) tienen entre un $41 \%$ y un 57
$\%$ menos de probabilidad de exportar que las empresas medianas y grandes, respectivamente. En relación con la edad y las ventas, cada año adicional de operación de la firma le permite incrementar su resultado exportador entre un 4-5\% y en ventas entre $6 \%$ al $11 \%$. Complementariamente se realizaron simulaciones sobre la probabilidad de exportar relacionando ambos factores para observar las sendas probabilísticas, representadas gráficamente sobre la Figura 3. Sin embargo, se utilizó otro indicador para representar el tamaño de la firma: el volumen de ventas, y se distribuyeron por cuantiles. Los resultados aprecian diferencias importantes en las sendas exportadoras de las empresas, siendo amplios los márgenes durante todos los años de operación de las firmas entre las empresas del primer cuantil y las del tercero, cuarto y quinto cuantil, cercanos al $50 \%$. 
Tabla 6. Resultados de las estimaciones. Modelo Logit.

Variable dependiente probabilidad de exportar.

\begin{tabular}{|c|c|c|c|c|c|c|c|c|}
\hline \multirow[t]{2}{*}{ Variable } & \multirow{2}{*}{$\begin{array}{c}\text { Característica } \\
\text { evaluada }\end{array}$} & \multicolumn{3}{|c|}{ Modelo Logit } & \multicolumn{3}{|c|}{ Modelo Probit } & \multirow{2}{*}{$\begin{array}{c}\text { Característica } \\
\text { Base }\end{array}$} \\
\hline & & \begin{tabular}{|c|} 
Coeficiente \\
\end{tabular} & Efecto Marginal & Sig. & Coeficiente & Efecto Marginal & Sig. & \\
\hline Concentración accionaria & Continua & -0.47 & -0.18 & 0.04 & -0.83 & -0.17 & 0.02 & \\
\hline Años de experiencia gerente & Continua & -0.17 & -0.08 & 0.00 & -0.36 & -0.06 & 0.00 & \\
\hline Log (capital por trabajador) & Continua & -0.13 & -0.07 & 0.01 & -0.26 & -0.05 & 0.00 & \\
\hline $\begin{array}{l}\% \text { Diversificación del } \\
\text { producto }\end{array}$ & Continua & -0.15 & -0.06 & 0.05 & -0.25 & -0.06 & 0.01 & \\
\hline Log (edad de la empresa) & Continua & 0.11 & 0.05 & 0.01 & 0.23 & 0.04 & 0.01 & \\
\hline Log (ventas por trabajador) & Continua & 0.29 & 0.06 & 0.00 & 0.55 & 0.11 & 0.00 & \\
\hline \multirow[t]{5}{*}{ Sector económico } & Alimentos & -1.90 & -0.39 & 0.00 & -3.52 & -0.39 & 0.00 & Textiles \\
\hline & $\begin{array}{l}\text { Metales y } \\
\text { maquinaria }\end{array}$ & -0.78 & -0.26 & 0.00 & -1.57 & -0.24 & 0.00 & \\
\hline & Químicos & -0.97 & -0.34 & 0.00 & -1.93 & -0.31 & 0.00 & \\
\hline & Plásticos & -1.04 & -0.25 & 0.00 & -1.64 & -0.27 & 0.00 & \\
\hline & \begin{tabular}{|c|} 
Otras \\
manufacturas \\
\end{tabular} & -1.38 & -0.37 & 0.00 & -2.75 & -0.36 & 0.00 & \\
\hline \multirow[t]{2}{*}{ Tamaño empresa } & \begin{tabular}{|l|} 
Mediana \\
\end{tabular} & 1.07 & 0.42 & 0.00 & 1.78 & 0.41 & 0.00 & Pequeña \\
\hline & Grande & 1.42 & 0.57 & 0.00 & 2.70 & 0.51 & 0.00 & \\
\hline \multirow[t]{3}{*}{ Tipo de empresa } & $\begin{array}{l}\text { Sociedad } \\
\text { Anónima }\end{array}$ & -0.96 & -0.42 & 0.00 & -1.82 & -0.36 & 0.00 & $\begin{array}{c}\text { Compañía } \\
\text { en bolsa }\end{array}$ \\
\hline & $\begin{array}{c}\text { Único } \\
\text { propietario }\end{array}$ & -1.04 & -0.30 & 0.00 & -1.73 & -0.31 & 0.00 & \\
\hline & Otros & -1.17 & -0.28 & 0.00 & -2.02 & -0.30 & 0.00 & \\
\hline Localización & $\begin{array}{l}\text { Resto de } \\
\text { Ciudades }\end{array}$ & -0.31 & -0.11 & 0.00 & -0.32 & -0.12 & 0.00 & $\begin{array}{l}\text { Ciudad } \\
\text { Capital } \\
\end{array}$ \\
\hline \begin{tabular}{|l|} 
Subsidiaria \\
\end{tabular} & No & 0.74 & 0.20 & 0.00 & 1.14 & 0.22 & 0.00 & $\mathrm{Si}$ \\
\hline \begin{tabular}{|l} 
Cuenta de ahorro \\
\end{tabular} & No & -0.53 & -0.38 & 0.00 & -0.85 & -0.17 & 0.01 & $\mathrm{Si}$ \\
\hline Acceso a financiamiento & No & -0.41 & -0.16 & 0.00 & -0.74 & -0.15 & 0.00 & $\mathrm{Si}$ \\
\hline Capacitación trabajadores & $\mathrm{Si}$ & 0.28 & 0.11 & 0.00 & 0.51 & 0.10 & 0.00 & No \\
\hline Certificación de calidad & No & -0.47 & -0.20 & 0.00 & -0.87 & -0.18 & 0.01 & $\mathrm{Si}$ \\
\hline
\end{tabular}




\begin{tabular}{|c|c|c|c|c|c|c|c|c|}
\hline \multirow[t]{2}{*}{ Variable } & \multirow{2}{*}{$\begin{array}{c}\text { Característica } \\
\text { evaluada }\end{array}$} & \multicolumn{3}{|c|}{ Modelo Logit } & \multicolumn{3}{|c|}{ Modelo Probit } & \multirow{2}{*}{$\begin{array}{c}\text { Característica } \\
\text { Base } \\
\end{array}$} \\
\hline & & Coeficiente & \begin{tabular}{|l|} 
Efecto Marginal \\
\end{tabular} & Sig. & \begin{tabular}{|l|} 
Coeficiente \\
\end{tabular} & Efecto Marginal & Sig. & \\
\hline Sitio web & No & -0.33 & -0.13 & 0.00 & -0.58 & -0.12 & 0.00 & $\mathrm{Si}$ \\
\hline Licenciado tecnología & No & -0.51 & -0.26 & 0.00 & -1.10 & -0.20 & 0.00 & $\mathrm{Si}$ \\
\hline \multirow[t]{3}{*}{ Número de competidores } & Uno & -1.80 & -0.03 & 0.00 & -3.66 & -0.03 & 0.00 & Ninguno \\
\hline & 2 a 5 & -1.45 & -0.07 & 0.00 & -2.57 & -0.07 & 0.00 & \\
\hline & más de 5 & -1.63 & -0.27 & 0.00 & -2.86 & -0.27 & 0.00 & \\
\hline Instituciones corruptas & $\begin{array}{c}\text { No está } \\
\text { de acuerdo }\end{array}$ & 0.18 & 0.09 & 0.00 & 0.40 & 0.07 & 0.00 & $\begin{array}{c}\text { Esta } \\
\text { de acuerdo }\end{array}$ \\
\hline & \multicolumn{2}{|c|}{ Constante } & \multicolumn{2}{|l|}{-0.37} & \multicolumn{2}{|c|}{-0.58} & & \\
\hline & \multicolumn{2}{|c|}{ Observaciones } & \multicolumn{2}{|l|}{10,960} & \multicolumn{2}{|c|}{10,960} & & \\
\hline & \multicolumn{2}{|c|}{ Chi cuadrado } & \multicolumn{2}{|l|}{2973.58} & \multicolumn{2}{|c|}{3960.90} & & \\
\hline & \multicolumn{2}{|c|}{ R2 de Macfadden } & \multicolumn{2}{|l|}{0.6038} & \multicolumn{2}{|c|}{0.6026} & & \\
\hline & \multicolumn{2}{|c|}{ Clasificaciones correctas } & \multicolumn{2}{|l|}{$90.04 \%$} & \multicolumn{2}{|c|}{$89.45 \%$} & & \\
\hline
\end{tabular}


Condiciones y determinantes de la internacionalización de lasempresas industriales . Héctor Alberto Botello Peñaloza - Isaac Guerrero Rincón

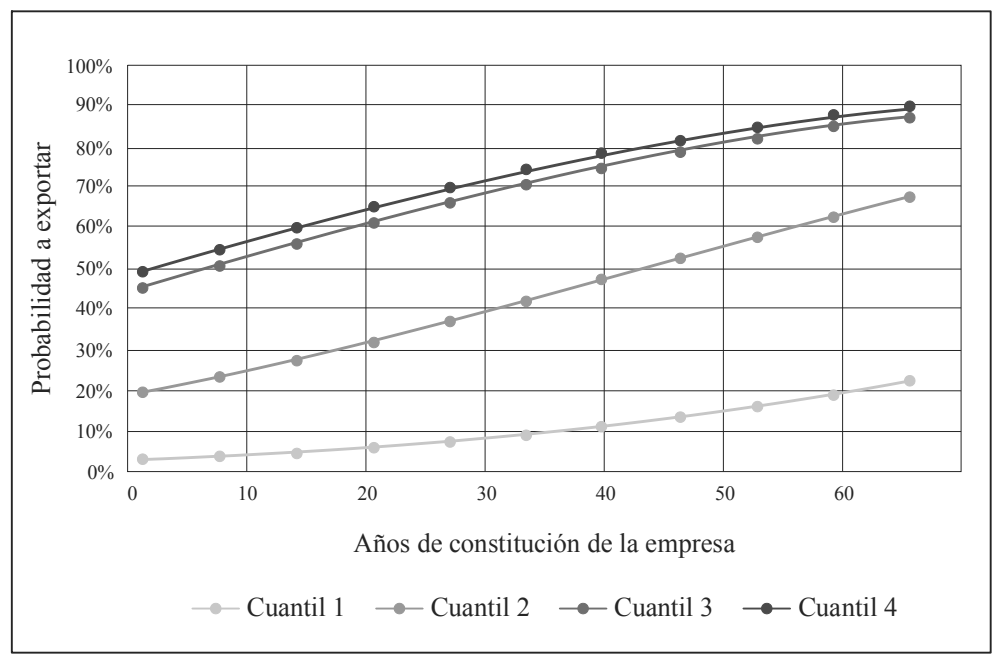

Figura 4. Tipo de exportaciones por cuantil de ventas de la empresa.

Fuente: cálculos del autor con base en la encuesta de empresas del Banco Mundial $(2006,2010)$.

En la segunda hipótesis, se aprecia que la inversión en tecnología tiene grandes influencias en la capacidad exportadora de la empresa al permitirle desarrollar ventajas competitivas diferenciadoras. Este módulo es el que tiene un impacto cuantitativo conjunto más significativo encontrado. En este sentido, si la firma posee sitio web, tiene una probabilidad adicional del $13 \%$ de exportar, frente a una que no lo tiene, mientras que la adopción de certificaciones de calidad, por su parte, aporta el $20 \%$. La presencia de software licenciado dentro de la firma aporta una probabilidad adicional del 26 $\%$ y las firmas que proveen capacitación de los trabajadores, un $11 \%$.

En relación con los factores institucionales, se aprecia que el acceso al crédito y la tenencia de cuenta bancaria les da a las empresas la capacidad de realizar transacciones de manera más ágil con el exterior, además de ayudarlas cuando los recursos financieros internos escasean, cuantitativamente su efecto se traduce en un aumento de la probabilidad en un $16 \%$ y un $38 \%$ respectivamente. A continuación se enseña el resultado de la opinión de los empresarios en relaciona con el sistema judicial. Si se piensa que un sistema judicial se encuentra parcializado, aumentarán los costes de transacción implícitos para las empresas, lo que hace más difíciles sus tratos con sus proveedores o distribuidores (North, 1990). En este sentido, los empresarios que estuvieron conformes con la afirmación, reportaron un crecimiento de un 7 a $9 \%$ de la capacidad a exportar. 
En los determinantes externos, se hallaron diferencias significativas en el nivel de internacionalización, dado el sector económico en el que se desenvolvían las empresas. El sector textil enseña una capacidad de internacionalización remarcable, un promedio del $30 \%$ por encima del resto de sectores, seguidos por los plásticos y los metales. Los sectores químicos y los alimentos fueron las ramas que mostraron los menores niveles con un -39 y $37 \%$ respectivamente.

Por otra parte, las empresas localizadas en ciudades capitales y de más de un millón de habitantes presentan entre un $3 \%$ y 6 $\%$ mejor probabilidad a exportar que las empresas en otras ciudades dentro de los países. Según Horta (2012), la explicación del anterior fenómeno se debe a las economías de escala que pueden alcanzar las empresas, dada la ubicación de los principales servicios de distribución, la infraestructura y la cercanía para realizar los trámites comerciales.

\section{CONCLUSIONES}

La internacionalización de las empresas es un fenómeno común dentro de una sociedad globalizada y un ingrediente importante en la mejora de la competitividad de las mismas, dado que les permite desarrollar y absorber capacidades que incrementen la calidad de sus mercancías y procesos de producción. En la última década, este proceso ha estado presente en las economías de América Latina, reflejado en un crecimiento significativo de la inversión extranjera directa y de los flujos comerciales; sin embargo esta expansión ha estado concentrada hacia las economías con grandes mercados internos (Brasil, México y Argentina) e impulsoras de la inversión (Chile y Colombia). La participación de la estructura productiva no se ha visto afectada de manera significativa por estos procesos; la región sigue exportando mayoritariamente productos primarios, aunque los bienes industriales han ganado espacio en algunos países, especialmente en aquellos donde el sector automotor tiene un papel importante.

Bajo este contexto, se reconoce que son las empresas las que han sido artífices de este proceso, y el presente documento buscó evaluar cuantitativamente los determinantes y condiciones de internacionalización haciendo una investigación sobre las empresas industriales colombianas entre el 2006 y 2010. En este sentido, la exploración del marco teórico y empírico sobre los determinantes de la internacionalización permitió establecer diversas hipótesis sobre el comportamiento de las empresas y sus factores internos y externos. En términos metodológicos, lo anterior se tradujo en el diseño de un modelo probabilístico para corroborarlas teniendo como referencia la encuesta del Banco Mundial del 2010 como fuente de datos y un modelo logístico como función de estimación estadística para la variable de análisis, que fue la decisión de exportar de la empresa. Las estimaciones sobre cerca de diez mil firmas arrojaron resultados que 
confirmaron cada una de las conjeturas establecidas, siendo los determinantes internos de las empresas los mayores determinantes en su decisión de internacionalizarse. De estos, sobresalen los componentes tecnológicos como componentes facilitadores y creadores de activos específicos para las firmas, por desempeñar un papel diferenciador en la estructura organizacional de la misma, lo que motiva su inmersión en el mercado externo. Entre los factores externos, se reconoció que un marco institucional de estabilidad jurídica y un acceso financiero por parte de la firma, permiten una mayor inserción internacional de esta; aunque los factores geográficos y sectores también tienen una influencia significativa.
Estos resultados deberían impulsar a las empresas de la región para que aprovechen las ventajas de la apertura comercial y la mayor inversión tecnológica con el objetivo de asegurar su presencia en otros países. Asimismo, la mejora de la infraestructura y el establecimiento de políticas empresariales que impulsen la renovación tecnológica de las firmas, pueden ser factores que contribuyan a una mayor internacionalización del sector industrial en los mercados exteriores, para impulsar así una reconversión productiva de Latinoamérica desde el sector primario al secundario, y generar mayores niveles de empleo y desarrollo económico para los países.

\section{Referencias}

Aaby, N. E. \& Slater, S. F. (1989). Management influences on export performance: a review of the empirical literature 1978-1988. International Marketing Review, 6(4).

Alonso, J. A. \& Donoso, V. (2000). Modelización del comportamiento de la empresa exportadora española. Información Comercial Española, (788), 35-58.

Ayouz, M. K. \& Remaud, H. (2003). The internationalization determinants of the small agrofood firms: hypotheses and statistical tests. International Food and Agribusiness Management Review, 5(2).

Banco Mundial (s.f.). Encuesta de empresas. Recuperado de http://espanol.enterprises urveys.org

Barber, J. P. \& Cobos, A. (2002). La aceleración del proceso de internacionalización de la empresa: el caso de las international new ventures españolas. Información Comercial Espanola-Monthly Edition-, 9-22.

Belso, J. A. (2003). Un análisis del proceso de internacionalización de las pequeñas y medianas empresas en la comunidad valenciana: modelo gradual versus acelerado. Revista Valenciana de Economía y Hacienda, (8), 191-209. 
Berger, E. (2013). Survival of the fittest: an assessment of the herfindahl index and product market competition. Retrieved from: http://eab7.web.rice.edu/research/ HHI_SSRN2014Full.pdf

Bilkey, W. J. (1978). An attempted integration of the literature on the export behavior of firms. Journal of International Business Studies, 9(1), 33-46.

Boisier, S. (2014). Polos de crecimiento: ¿están muertos? Revista EURE-Revista de Estudios Urbano-Regionales, 8(24).

Calvo, F. J. S. (2012). Evolución y mejora en la competitividad de las empresas del sector textilconfección. Economía Industrial, (385), 39-46.

Chetty, S. K. \& Hamilton, R. T. (1993). Firm-level determinants of export performance: a metaanalysis. International Marketing Review, 10(3).

Christensen, C. H., Da Rocha, A. \& Gertner, R. K. (1987). An empirical investigation of the factors influencing exporting success of Brazilian firms. Journal of International Business Studies, 61-77.

Coase, R. H. (1937). The nature of the firm. Economica, 4(16), 386-405.

Comisión Económica para América Latina -CEPAL-. (2000-2014). Estadísticas. Recuperado de http://estadisticas.cepal.org/cepalstat/WEB_CEPALSTAT/Portada.asp

Comisión Económica para América Latina y el Caribe_CEPAL- (2013). Anuario 2013.

Dhanaraj, C. \& Beamish, P. W. (2003). A resource based approach to the study of export performance. Journal of Small Business Management, 41(3), 242-261.

Dunning, J. H. (1973). The determinants of international production. Oxford Economic Papers, 289-336.

Dunning, J. H. (1988). The eclectic paradigm of international production: a restatement and some possible extensions. Journal of International Business Studies, 19(1), 1-31.

Dunning, J. H. (1999). Trade, location of economic activity and the multinational enterprise: a search for an eclectic approach. En P.J. Buckley \& P. Ghauri. The internationalization of the firm (p. 61-79). Recuperado de: http://www.elgaronline.com/view/1840647000.00001.xml

Durán, J. J. \& Ubeda, F. (1997). La inversión directa española en Marruecos. Economía Exterior, (3), 149-158.

Durán, J. J. (1987). Decisiones de inversión directa en el exterior de la empresa española 19791985. Información Comercial Española, (643), 73-86.

Fondo Monetario Internacional. (s.f.). Estadísticas. Recuperado de http://www.imf.org/external/ data.htm 
Galán, J. I., Galende del Canto, J. \& González, J. (2000). Factores determinantes del proceso de internalización. El caso de Castilla y León comparado con la evidencia española. Economía Industrial, (333), 33-48.

García, B. F. (1994). Problemas de competitividad del sector exportador valenciano. Revista de Estudios Regionales, (39), 115-138.

García, J., López, D. C., Uribe, E. M. \& Umaña, P. E. (2014). Una visión general de la política comercial colombiana entre 1950 y 2012 (No. 011188). Bogotá: Banco de la República.

Gemünden, H. G. (2013). Success factors of export marketing. Perspectives on international marketing-re-issued. RLE International Business, 29, 33.

Geringer, J. M., Tallman, S. \& Olsen, D. M. (2000). Product and international diversification among Japanese multinational firms. Strategic Management Journal, 21(1), 51-80.

Gertner, R. K., Gertner, D. \& Guthery, D. (2007). The implications of export performance measurement for the significance of the determinants of export performance: an empirical investigation of Brazilian firms. Journal of Global Marketing, 20(1), 21-38.

Gomes, L. \& Ramaswamy, K. (1999). An empirical examination of the form of the relationship between multinationality and performance. Journal of International Business Studies, 173-187.

Graña, F. M., Liseras, N., De Rearte, M. A. \& Barberis, F. (2010). Competitividad de las firmas del sector textil-confecciones orientadas a moda y diseño. Recuperado de http:// nulan.mdp.edu.ar/1460/1/01275.pdf

Horta, R. (2012). Determinantes internos y externos del resultado exportador a nivel de firma: análisis de empresas agroindustriales uruguayas. Uruguay: Publicaciones Instituto de Competitividad, Universidad Católica del Uruguay.

Johanson, J. \& Vahlne, J. E. (1990). The mechanism of internationalisation. International Marketing Review, 7(4).

Johanson, J. \& Wiedersheim-Paul, F. (1999). The internationalization of the firm-four Swedish cases. The internationalization of the firm, 27-42.

Lages, L. F. \& Lages, C. R. (2004). The STEP scale: a measure of short-term export performance improvement. Journal of International Marketing, 12(1), 36-56.

Leonidou, L. C., Katsikeas, C. S. \& Samiee, S. (2002). Marketing strategy determinants of export performance: a meta-analysis. Journal of Business Research, 55(1), 51-67.

López, C. (1997). Internacionalización de la empresa española mediante inversión directa en el exterior. 1988-1994. Economía Industrial,(318), 141-150. 
Louter, P. J., Ouwerkerk, C. \& Bakker, B. A. (1991). An inquiry into successful exporting. European Journal of Marketing, 25(6), 7-23.

Lu, J. W. \& Beamish, P. W. (2001). The internationalization and performance of SMEs. Strategic Management Journal, 22(67), 565-586.

Madsen, T. K. (1987). Empirical export performance studies: a review of conceptualizations and findings. Advances in International Marketing, 2, 177-198.

Medina, E. (2003). Modelos de elección discreta. Publicaciones Económicas de la Universidad Autónoma de Madrid, 26.

Mendoza J. (2008, nov.) Determinantes del proceso de internacionalización de las PYME peruanas: caso sector confecciones. Economía y Sociedad CIES, 69.

Meyer-Stamer, J. (2005). Systematic competitiveness revisited. Conclusions for technical assistance in private sector development. Duisburg: Mesopartner (mimeo).

North, D. C. (1990). Institutions, institutional change and economic performance. Cambridge: Cambridge University Press.

Pérez, C. (2005). Métodos estadísticos avanzados con SPSS. Madrid: Thompson.

Peters, E. D. (2004). Propuestas de política para mejorar la competitividad y la diversificación de la industria maquiladora de exportación en Honduras ante los retos del CAFTA (Vol. 24). United Nations Publications.

Pinon, M. M., Mejía, M. A. L., Garza, M. \& Delgado, M. F. L. (2012). Central America, Panama, and the Dominican Republic: Challenges Following the 2008-09 Global Crisis. International Monetary Fund.

Porter, M. E. (1991). La ventaja competitiva de las naciones (Vol. 1025). Buenos Aires: Vergara.

Renau, J. J. (1996). El porqué, el cómo y el dónde de la internacionalización de la empresa. Revista Asturiana de Economía, 6, 41-62.

Reyes, G. (2013). Procesos de integración en América Latina y el Caribe: caracterización general y potencialidad de nuevos ejes de integración. Revista Tendencias, 8(2).

Ruigrok, W. \& Wagner, H. (2003). Internationalization and performance: An organizational learning perspective. MIR: Management International Review, 63-83.

Sambharya, R. B. (1995). The combined effect of international diversification and product diversification strategies on the performance of US-based multinational corporations. MIR: Management International Review, 197-218.

Shoham, A. (1998). Export Performance: A Conceptualization and Empirical Assessment. Journal of International Marketing, 6(3). 
Sousa, C. M., Martínez López, F. J. \& Coelho, F. (2008). The determinants of export performance: A review of the research in the literature between 1998 and 2005. International Journal of Management Reviews, 10(4), 343-374.

Suárez, S. M., Olivares, A. \& Galván, I. (2002). La expansión de mercados de exportación y el tamaño empresarial: el caso de las empresas exportadoras canarias. Información Comercial Española, (802), 83-97.

Verwaal, E. \& Donkers, B. (2002). Firm size and export intensity: Solving an empirical puzzle. Journal of International Business Studies, 603-613.

Voerman, J. A. (2004). The export performance of European SMEs. Netherlands: University Library Groningen.

Wang, C. H., Hsu, L. C. \& Fang, S. R. (2008). The determinants of internationalization: Evidence from the Taiwan high technology industry. Technological forecasting and social change, 75(9), 1388-1395.

Zou, S. \& Stan, S. (1998). The determinants of export performance: a review of the empirical literature between 1987 and 1997. International Marketing Review, 15(5), 333-356.

Zou, S., Taylor, C. R. \& Osland, G. E. (1998). The EXPERF scale: a cross-national generalized export performance measure. Journal of International Marketing, 37-58. 